\title{
Cognitive appraisal, Coping, Stress and Fear Contracting Covid-19 in Working People in Pakistan
}

\author{
Anam Ali ${ }^{1}$ D Ali Asad Khan ${ }^{2} \cdot$ Sadia Abbas $^{3}$ - Ali Salman Khan ${ }^{4}$ Ehsan Ullah ${ }^{1}$
}

Accepted: 29 October 2021 / Published online: 19 November 2021

(c) The Author(s), under exclusive licence to Springer Science+Business Media, LLC, part of Springer Nature 2021

\begin{abstract}
The present study aimed to examine the relationship and prediction of cognitive appraisal and coping with Stress and Fear contracting COVID-19 among the working population of Pakistan. Cross-sectional research design was employed. The data was collected from 980 participants of almost 39 different professions using the purposive sampling technique. Stress Appraisal Measure (Peacock et al., in Stress Med 6:227-236, 1990, http://www.drpaulwong.com/wp-content/uploads/2018/03/StressAppraisal-Measure-SAM-Peacock-Wong-1990-Paper.pdf). Brief COPE Inventory (Caver, in Int J Behav Med 4:92-100, 1997), and Perceived Stress Scale (Cohen et al., in J Health Soc Behav 24:385-396, 1983) were used to measure cognitive appraisal, coping, and stress, respectively. Fear was measured by using Fear contracting COVID-19 questionnaire (Ali et al., in J Pakistan Soc Int Med 2(2):140144, 2021). Age, education, and previously attended stress management training were significantly positively correlated with stress and fear. Females were more stressed and fearful than males. Average time spent on social media was significantly positively correlated with stress. Participants, who were employed, had family members of the older age group above 50 years and had family members with the history of biological diseases were more fearful. Results of hierarchical multiple regression analyses showed that threat, centrality, stressfulness appraisal, and avoidant emotional coping significantly positively predicted stress, whereas controlself appraisal and active emotional coping significantly negatively predicted stress. Moreover, threat, challenge, centrality, stressfulness appraisal, and problem-focused coping significantly positively predicted fear contracting COVID-19, whereas control-self appraisal and active emotional coping significantly negatively predicted fear contracting COVID-19 after controlling for covariates. This study will address the administrative authorities and government institutions to provide first-aid mental health services for emergencies, epidemics, or pandemics in the future.
\end{abstract}

Keywords Cognitive appraisal · Coping $\cdot$ COVID-19 $\cdot$ Fear $\cdot$ Stress

Extended author information available on the last page of the article 


\section{Introduction}

The widely spread Covid-19 is a contagious respiratory disease, and the effects of the virus vary from person to person. Normal individuals usually experience mild to moderate symptoms of respiratory disturbance and recover after taking precautionary measures. The best way to prevent this disease is by washing hands or frequently sanitizing, covering the face while coughing or sneezing, maintaining the distance of $1 \mathrm{~m}$ from the person who is coughing or sneezing, staying at home, and practicing social distance by limiting unnecessary outdoor travels and meetings (World Health Organization WHO, 2020). On January 31st, 2020, World Health Organization (WHO) declared the novel Covid-19 Pneumonia of China as a Public Health Emergency of International Concern (Qui, et al., 2020). And on March 11, 2020, Covid-19 is declared a pandemic by WHO because of more than 118,000 cases of Covid-19 in more than 110 countries and territories worldwide and continued risk of global spread (Ducharme, 2020). To control this widely spread pandemic of Covid-19, WHO recommended social distancing to all the sufferers. So, almost all countries around the world implicated lockdown for practicing social distance (WHO, 2020).

Lockdown is defined as a situation in which people are not permitted to enter or leave their houses or an area freely because of any emergency situation by Cambridge Dictionary ('Lockdown', 2020). It was observed that schools have been imposing safety actions for decades in the form of locking down their systems to prevent and prepare for the threats. According to a recent Washington Post article, a total of 4.1 million children and youth, including students and teachers, experienced lockdowns during 2017-2018 in the United States according to a recent report of Washington Post article. Lockdowns can be considered helpful in critical emergencies and can protect people from life threats. However, they may cause stress, anxiety, frustration, fatigue, and post-traumatic symptoms, particularly in teachers (National Association of School Psychologists NASP, 2018).

In Pakistan, a country-wide lockdown has been announced from 23rd March 2020 till 11th August 2020 to scrub the widely spread Covid-19 pandemic. This lockdown is applied to all private and government institutions, including schools, colleges, universities, banks, trading markets, construction companies, business communities, transportation services, garments shops, and shopping malls except pharmacy, grocery, and eatables' shops (Anadolu, 2020). This lockdown laid a great negative impact on mental health and caused great stress and fear among all those professionals who were self-employed or working on daily wages, including teachers, professors, mental health workers, emergency workforces, etc. (Khatak, 2020).

Stress is defined as the mental press and tension and could be external from the outside environment or caused by internal perceptions of the individuals. During the lockdown condition of COVID-19, individuals are experiencing both types of stress that result in anxiety, worry, depressive symptoms, fear, and tension. Mostly, all working populations are suffering as they are more vulnerable to mental health problems due to work-related stress and stress of the COVID-19 pandemic (Babore et al., 2020). 
Along with stress, another common response towards the COVID-19 pandemic is seen as fear of contracting this infection. Fear is the most common and known way of people's reaction towards infectious outbreaks in which individuals react in their subjective ways (Usher et al., 2020). The people's perception of COVID-19 as a fear factor was assessed from 96 participants of 11 different countries, and the results revealed that people perceived the COVID-19 pandemic in three different ways; as a virus never seen before (31.3\%), biological weapon (29.2\%) and as God's punishment and Devil's tactics (19.8\%) causing medium to a high level of fear among $77 \%$ of the participants (Egunjobi, 2020). Mertens et al. (2020) reported intolerance of uncertainty, worry, concern for personal health, the risk for family, and media exposure as predictors of fear during the outbreak of COVID-19.

A study framework was conceptualized for the present study based on previous literature and Lazarus and Folkman (1987)'s proposed model of stress and coping. According to Lazarus and Folkman's (1984) theory of cognitive appraisal and coping, the individual's response to any stressor is processed through two cognitive appraisals (primary and secondary appraisal), resulting in the selection of coping strategies by the individual to deal with the stressor. Cognitive appraisal plays an important role in people's perception during stressful situations (Fig. 1). Research study on the Chinese public revealed that three cognitive appraisals of public's knowledge, perceived severity, and perceived controllability of COVID-19 were differentially related to negative and positive emotions, behavioral reactions of substance use, aggression, phone use, sleep problems, social participation, and precautionary behavior (Li et al., 2020).

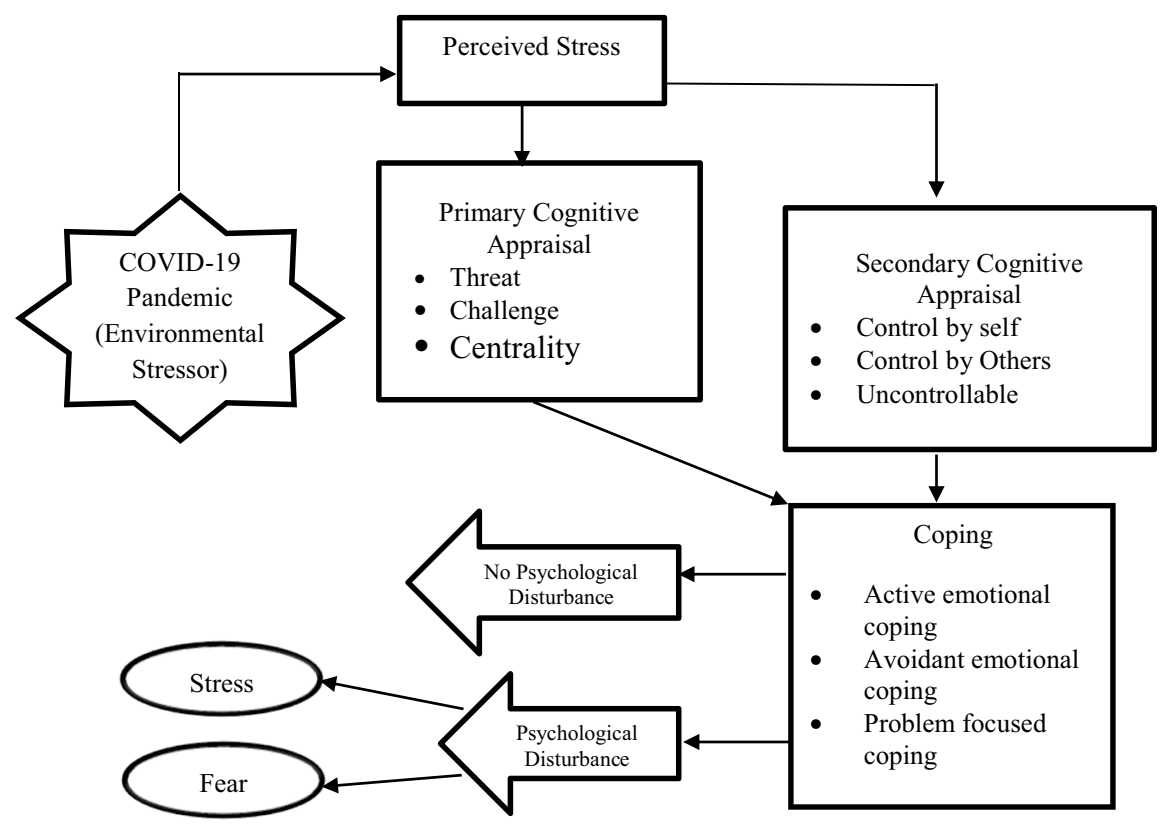

Fig. 1 Conceptualized research framework. Source: Author's estimation 
According to the transactional model of stress and coping, coping is a process involving cognitive and behavioral responses used by the individual in reaction to the internal/external stressor that is perceived to exceed their resources. Coping responses lie under two categories, i.e., Emotion-focused coping and Problem-focused coping (Lazarus \& Folkman, 1987). The research study assessing the coping strategies used by the medical health professionals handling the patients of COVID-19 and those working in non-COVID-19 departments revealed that positive appraisal and planning were frequently used coping strategies used by the participants (Man et al., 2020). Shanahan et al. (2020) revealed coping strategies were maintaining a daily routine and positive reappraisal to reduce stress among young adults during COVID-19.

With the onset of Covid-19 in Pakistan, doctors, nurses, paramedical staff, and psychologists are experiencing physical, emotional, and psychological stress, including a high risk of infection, inadequate safety equipment, frustration, homesick and mental health problems. The continuous exposure to a stressed environment has been exerting great mental pressure, distress, anxiety, fear, panic attacks, sleep problems, depressive symptoms, irritability, and interpersonal relationship problems among healthcare professionals. The mental pressure of being stigmatized and discriminated against has increased drastically when a health care professional is suddenly affected with Covid-19 (Zheng, 2020).

The past literature suggests that teaching professionals experiencing lockdown feel more stressed, feared, and overwhelmed than other workers and professionals. A research finding suggested by the National foundation of educational research revealed that one out of five teachers reported being tensed and stressed compared to one out of eight workers in similar professions. Moreover, the study also suggested that working for extra weeks of the year intends to have higher stress levels and poor work-life balance (Busby, 2019).

Bankers are also facing occupational stress and burnout worldwide, especially in Pakistan's banking sector. It is revealed from a research study that banking employees are experiencing job worries, working hours, and workload as significant stressors. These stressors resulted in burnout symptoms of fatigue, headache, and disturbed sleep among the bankers (Khattak et al., 2011).

Literature provides knowledge about stress and coping responses used by the mental health professionals and general public during the COVID-19 pandemic. However, less is known about the working population. As per researcher's knowledge, there is dearth of research on association of cognitive appraisal and coping with stress and fear due to COVID-19 pandemic in working population. No available studies directly addressed the relationship of these variables in Pakistan. So, this study aimed to examine the association of cognitive appraisal and coping with Stress and Fear of contracting COVID-19 in the working population of Pakistan. It will help address the general public's emotional and psychological problems. It will direct the public policymakers to prepare first aid mental health treatments for emergencies, epidemics, or pandemics in the future. 


\section{Hypothesis}

- Cognitive appraisal and coping are likely to be associated with stress and fear contracting COVID-19

- Cognitive appraisal and coping are likely to predict stress and fear after controlling for covariates

\section{Method}

A cross-sectional research design was used in the present study. A sample size of 980 working employees such as teachers, engineers, managers, doctors, bankers, accountants, business people, lawyers, civil servants, government employees were collected through the purposive sampling technique. Out of 980 participants $\left(M_{a g e}=29.64, S D=8.11\right), 69.2 \%$ were females. Among those, the majority were educated $\left(M_{e d u}=16\right.$ years, $\left.S D=1.97\right)$, single $(49.8 \%)$, employed $(80.7 \%)$, and belonged to the nuclear family system (53.4\%). People doing any job, full time or part-time job, government or private job, or self-employed were included in the study. Students who were unemployed and unemployed people or housewives were excluded. People with diagnosed psychiatric illnesses were also excluded.

\section{Measures}

\section{Stress Appraisal Measure (SAM; Peacock \& Wong, 1990)}

Stress Appraisal Measure was used to assess the cognitive stress appraisal of COVID situation being the anticipatory stressor. It comprised of 28 items with 5 points Likert scale (from not at all to extremely). It consists of 7 subscales: threat, challenge, centrality, control by self, control by others, uncontrollability, and stressfulness. Reliability of the subscales of cognitive appraisal ranged from 0.70 to 0.86 (Durak \& Senol-Durak, 2013).

\section{Brief COPE Inventory (Brief Cope; Caver, 1997)}

The Brief COPE Inventory is a multidimensional coping inventory used to assess a broad range of people's coping responses to stress (Carver, 1997). It consists of 28 items which are scored on a four-point Likert scale. It comprises 14 subscales, having two items in each subscale (Carver, 1997). Based on the conceptual and empirical literature, the 14-subscales were grouped into emotion-focused coping and problem-focused coping. Emotion-focused coping is divided into active emotional coping and avoidant emotional coping. Three coping strategies are active emotional coping (includes venting, positive reframing, humor, acceptance, and emotional support strategies), avoidant emotional coping (includes self-distraction, denial, behavioral disengagement, self-blame, and substance use), and problem-focused coping (includes planning, instrumental support, active coping and religion) (Alhurani 
et al., 2018) were used in the present study. Cronbach alpha for the brief COPE in the present study was found to be 0.86 .

\section{Perceived Stress Scale (PSS; Cohen et al., 1983)}

It was used to measure the perceived stress of the COVID-19 situation. It consists of 10 items with a 5 Likert scale (from never to very often). There is reverse scoring of few items of PSS. Individual scores on PSS can range from 0 to 40, with higher scores indicating higher perceived stress. The reliability coefficient in the present study was 0.88 .

\section{Fear Contracting COVID-19 Questionnaire (FCCQ; Ali et al., 2021)}

An indigenous questionnaire of fear of COVID-19 was used to measure the intensity of fear experienced by people. It was comprised of 4 items which were scored on 5 points Likert scale (from never to always). The participants were asked to rate how much fear they experience because of COVID-19. The total score is obtained by summing up all the items; the greater the score, the greater the fear. Cronbach alpha of the scale in the present study was found to be 0.81 .

\section{Demographic Questionnaire}

This questionnaire was designed to obtain basic information regarding participants' age, gender, education, marital status, employment status, family system, accommodation, the main source of information about COVID-19, and average time spent on TV news related to COVID-19, etc.

\section{Procedure}

Data was collected through the web from April 2020 to July 2020 after the approval from Institutional Review Board. The online form was sent to different working people through social media (Facebook, Whats app, messenger, etc.), and they were requested to fill the form and forward it to other people. Written informed consent was taken from the participants as an ethical responsibility. Participants were debriefed about the nature of the research, their role in the study and informed about the research purpose with a paragraph at the start of the Google form. The email address was also given to ask any questions related to the research question. Participants were assured about the confidentiality of their responses and their identity. It was made clear that the information was used only for education and research purposes. After that, the participants were asked to fill out a demographic form and all the questionnaires. 25.0 version of SPSS (Statistical Package for Social Sciences) was used for descriptive statistics and related analysis. 
Table 1 Sociodemographic and COVID-19 related characteristics of employees

\begin{tabular}{|c|c|c|}
\hline Characteristics & $n$ & $\%$ \\
\hline \multicolumn{3}{|l|}{ Gender } \\
\hline Male & 302 & 30.8 \\
\hline Female & 678 & 69.2 \\
\hline \multicolumn{3}{|l|}{ Education } \\
\hline Matric & 13 & 1.3 \\
\hline Intermediate & 48 & 4.9 \\
\hline Bachelors & 232 & 23.7 \\
\hline Masters & 421 & 43.0 \\
\hline M. Phil & 238 & 24.3 \\
\hline $\mathrm{Ph} \mathrm{D}$ & 28 & 2.9 \\
\hline \multicolumn{3}{|l|}{ Marital status } \\
\hline Single & 488 & 49.8 \\
\hline Married & 477 & 48.7 \\
\hline Separated & 4 & 0.4 \\
\hline Divorced & 7 & 0.7 \\
\hline Widowed & 4 & 0.4 \\
\hline \multicolumn{3}{|l|}{ Employment } \\
\hline Employed & 791 & 80.7 \\
\hline Self-employed & 189 & 19.3 \\
\hline \multicolumn{3}{|l|}{ Family system } \\
\hline Nuclear & 523 & 53.4 \\
\hline Joint & 457 & 46.6 \\
\hline \multicolumn{3}{|l|}{ Accommodation } \\
\hline Own & 723 & 73.8 \\
\hline Rental & 257 & 26.2 \\
\hline \multicolumn{3}{|l|}{ Main source of information about COVID-19 } \\
\hline Whatsapp & 165 & 16.8 \\
\hline Facebook & 117 & 11.9 \\
\hline TV news & 543 & 55.4 \\
\hline Twitter & 30 & 3.1 \\
\hline Scientific papers & 69 & 7.0 \\
\hline e-newspapers & 56 & 5.7 \\
\hline Family members of older age group above 50 years ${ }^{a}$ & 815 & 83.2 \\
\hline $\begin{array}{l}\text { Family members having a history of the biological } \\
\text { disease (like heart disease, diabetes, pneumonia, } \\
\text { asthma, hepatitis, etc. }{ }^{\text {a }}\end{array}$ & 624 & 63.7 \\
\hline Previously attended any stress management training ${ }^{a}$ & 180 & 18.4 \\
\hline
\end{tabular}

$N=980$

${ }^{\mathrm{a}}$ Reflects the number and percentage of participants answering yes to this question 


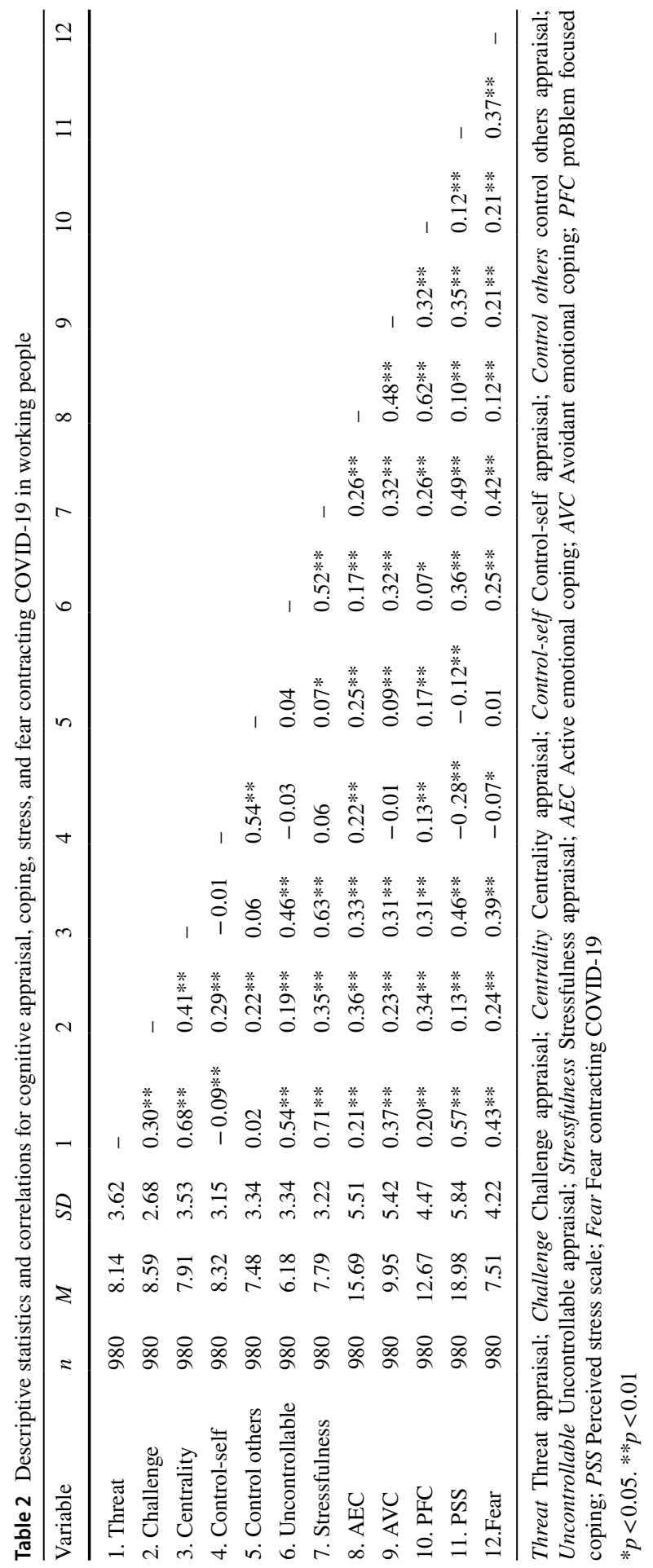




\section{Results}

Table 1 shows COVID-19 related characteristics of participants. The majority of the participants $(55.4 \%)$ reported that the main source of information about COVID-19 was TV news. The average time spent on social media on COVID-19 related articles/news was approximately $1 \mathrm{~h}$ per day. Eighty-three percent of the participants have family members of older age group above 50 years, and $63.7 \%$ reported having a history of biological diseases. Only $18.4 \%$ of the participants had previously attended any stress management training.

Table 2 shows the correlation of cognitive appraisal, coping, stress, and fear contracting COVID-19 among working employees. It was found that all cognitive appraisal scales were significantly positively correlated with active emotional coping and problem-focused coping. It was also found that all cognitive appraisal scales other than control-self were significantly positively correlated with avoidant emotional coping. It was also found that all primary appraisal scales, uncontrollable appraisal, and all three coping strategies were significantly positively correlated with perceived stress and fear. In contrast, controlself and control others appraisal were significantly negatively correlated with perceived stress and fear of contracting COVID-19 (see Table 2).

Table 3 shows the correlation of demographic variables with stress and fear contracting COVID-19. Results showed that age was significantly negatively correlated with perceived stress and fear, which means that as age increases, stress and fear of COVID-19 decreases. Gender was significantly positively correlated with perceived stress and fear, indicating that females were more stressed and fearful of COVID-19 than males. Education was significantly negatively correlated with perceived stress and fear, which means that as education increases, stress and fear of COVID-19 decreases. Average time spent on social media was significantly positively correlated with stress which means that as time spent on social media on COVID-19 related articles/news increases, stress was also increased. Family members of the older age group were significantly negatively correlated with fear, which means that participants who have family members of older age group above 50 years were more fearful of contracting COVID-19 than participants who didn't have. Family members' history of biological diseases (like heart disease, diabetes, pneumonia, asthma, hepatitis, etc.) was significantly negatively correlated with fear. Participants whose family members have history of biological diseases were more fearful than those who didn't. Stress management training was significantly positively correlated with stress and fear of contracting COVID-19, which depicts that participants who didn't previously attend any stress management training were more stressed and fearful of COVID-19 than those who previously attended it (see Table 3).

Table 4 shows the results of Hierarchical Multiple Regression Analysis (Enter Method). It was found that threat, centrality, stressfulness appraisal, and avoidant emotional coping significantly positively predicted stress, whereas controlself appraisal and active emotional coping significantly negatively predicted stress after controlling for covariates. 


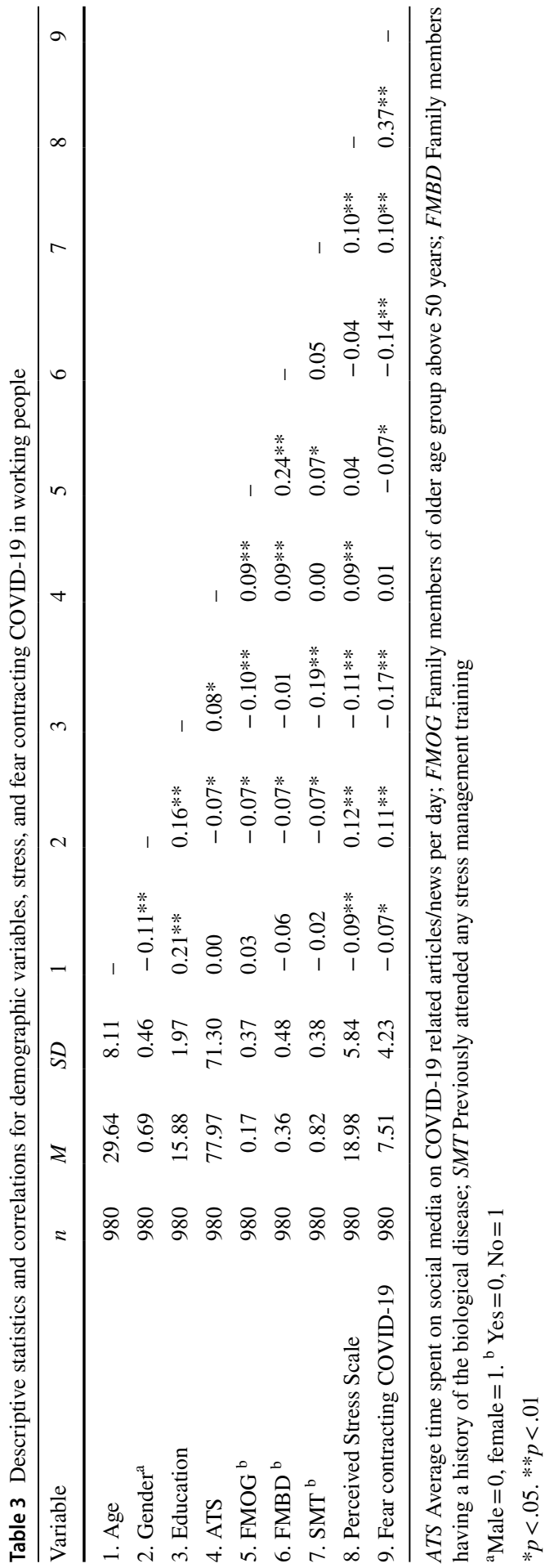




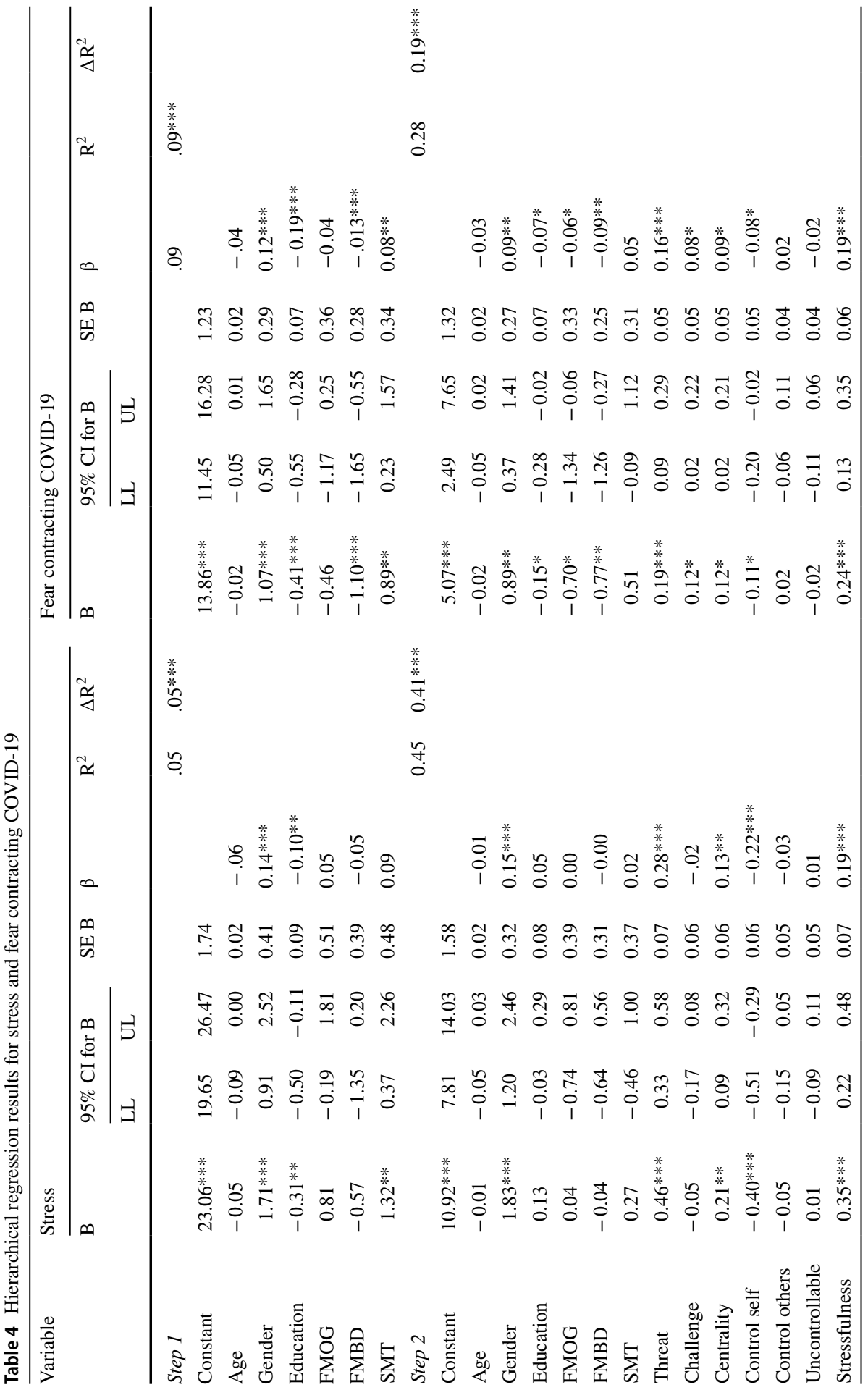




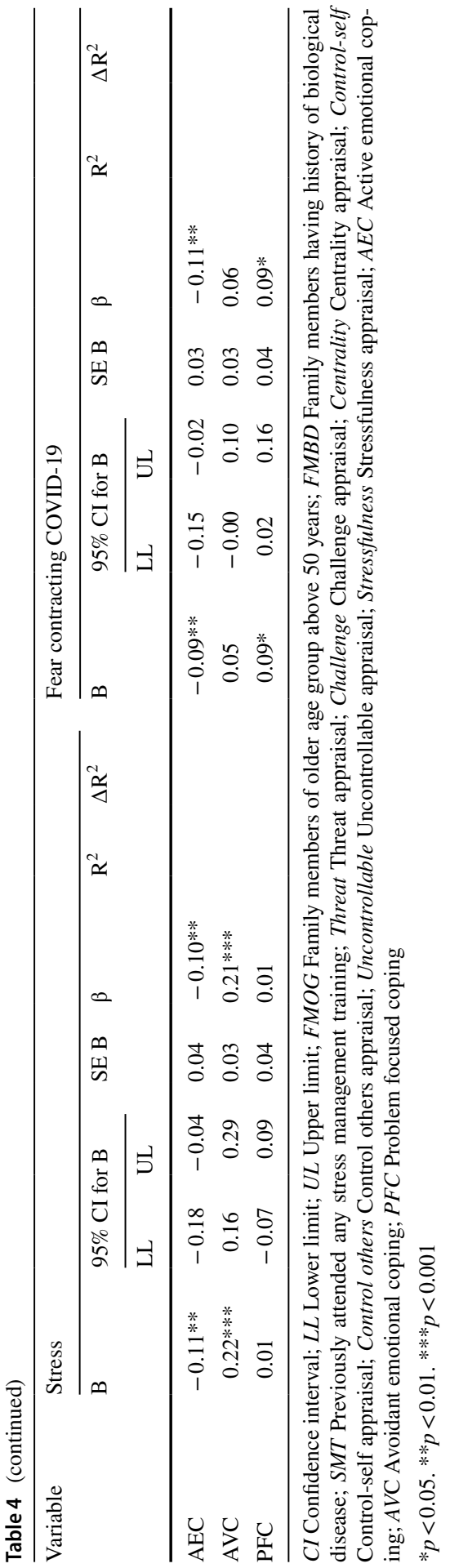


For Fear contracting COVID-19, results showed that threat, challenge, centrality, stressfulness appraisal, and problem-focused coping significantly positively predicted fear contracting COVID-19. In contrast, control-self appraisal and avoidant emotional coping significantly negatively predicted fear contracting COVID-19 after controlling for covariates (see Table 4 for values of standardized beta, $\Delta \mathrm{R}^{2}, \mathrm{R}^{2}$ ).

\section{Discussion}

It was hypothesized that cognitive appraisal and coping are likely to predict stress after controlling for covariates. This hypothesis was partially supported. Results revealed that threat, centrality, and stressfulness appraisal, as well as avoidant emotional coping, were significant positive predictors of Stress in the working population during lockdown of COVID-19. This finding of the present study can be related to Babore et al. (2020), whose study revealed that lower positive attitudes towards stress and avoiding coping strategies were predicted higher levels of distress among healthcare professionals during the COVID-19 outbreak. Another research study revealed that health professionals' escape avoidance coping strategy is related to stress and burnout among mental health workers (Thornton, 1992). Moreover, the general public started avoiding and limited their participation in COVID-19 related events to reduce their stress (Li et al., 2020). Concerning to threat, centrality, and stressfulness appraisal being the positive predictors of Stress of COVID-19 among the participants, this is the new finding in the present study as per the researcher's knowledge; almost all previous documented data did not provide any information regarding the subscales of cognitive appraisal as predictors for Stress during COVID-19 pandemic. But some studies reported that the Chinese public knowledge, perceived severity, and controllability of COVID-19 were those three cognitive appraisals related to emotional and behavioral reactions, social participation, and precautionary behaviors differently (Li et al., 2020).

Results also revealed that control-self appraisal and active emotional coping were significant negative predictors for Stress. These findings of the present study were supported with the cognitive-phenomenological theory by Lazarus and Folkamn (1986) that suggests two critical processes of cognitive appraisal and coping are the important mediators in stressful person-environment relations. During the cognitive appraisal, an individual evaluates the significance of the stressor/environment using two types of appraisals. Primary appraisal decides the importance of the environment/stressor for the individual as stressful or irrelevant. If the stressor is stressful, then secondary appraisal becomes functional, and the individual tries their best to cope with the stressful situation by using coping mechanisms that reduce stress and disturbing emotions. The present study findings are also supported by many research studies in which it was reported that cognitive appraisal has a significant role in determining coping strategies opted by the individual to deal with their disturbing emotions of stress, discomfort, constraint, tension (Dewe, 1991) and burnout, workstress among mental health workers (Thornton, 1992). Furthermore, the literature does not provide any documented research regarding the predictive relationship of 
control- self appraisal with stress regarding the COVID-19 pandemic. However, the primary and secondary appraisal proved to be a significant predictor for tension and stress in stressful work encounters (Dewe, 1991).

In the present study, active emotional coping (includes venting, positive reframing, humor, acceptance, and emotional support strategies) was found to be the negative predictor of stress. Humor in emergency work situations can help the workers adjust to difficult, demanding and empowering situations, increase social work communication, and helps in cognitive reframing and social support (Moran \& Massam, 1997). Furthermore, using humor in social situations can help gain social support that reduces the effects of distress (Moran \& Hughes, 2006). Moreover, the general public actively engaging in precautionary behaviors related to COVID-19 to deal with their distressing behavioral and emotional reactions (Li et al., 2020). Shanahan et al. (2020) conducted a research study to assess the emotional distress among young adults during COVID-19. The revealed coping strategies were maintaining a daily routine and positive reappraisal to reduce stress. As far as the coping mechanisms and stress are concerned related to COVID-19, the literature suggests many types of research in this aspect, but most of them are related to health professionals, as Man et al. (2020) and Babore et al. (2020) assessed the coping strategies and high level of stress among the health care professionals after the 1st month of COVID-19 outbreak.

Moreover, active emotional coping (positive reappraisal) was frequently used by health care professionals than in the general population. Another study conducted by Chew et al. (2020) identified common themes of fear, depression, stigmatization, stress symptoms, and a greater sense of empowerment and compassion in the narrative synthesis of 18 studies related to infectious diseases outbreak of Ebola epidemic and H1N1outbreak. Emotion-focused coping strategies of positive appraisal and seeking social support were also identified.

It was also hypothesized that cognitive appraisal and coping predict fear contracting COVID-19 after controlling for covariates. This hypothesis was partially supported. The present study found that threat, challenge, centrality, and stressfulness appraisal positively predicted Fear contracting COVID-19 among the participants. Literature supports the predictors of fear as in an online study conducted in March 2020, during the outbreak of COVID-19, intolerance of uncertainty, worry, concern for personal health, the risk for family, and media exposure were revealed as predictors of fear (Mertens et al., 2020). Furthermore, the public's perception of the COVID-19 pandemic as a fear factor in participants of 11 countries revealed that COVID-19 caused medium to a high level of fear in $77 \%$ of the participants as they perceived the COVID-19 pandemic as a virus never seen before, biological weapon and as God's punishment and Devil's tactics (Egunjobi, 2020). However, the indepth analysis of subscales of cognitive appraisal and coping construct related to stress and fear of contracting COVID-19 has not been studied yet, which is the new addition in the literature that needs to be further explored.

Results also revealed that problem-focused coping was a significant positive predictor of fear contracting COVID-19 among the participants. According to Lazarus and Folkman (1984), problem-focused coping manages the stressor by altering the distressing stimulus or environment. 
It was also found in the present study that control-self appraisal and avoidant emotional coping were significant negative predictors for Fear contracting Covid-19 among the participants. Control by self aims to identify and investigate the possible resources to deal with the stressor as described by Lazarus and Folkman (1984). In the present study, avoidant emotional coping was a negative predictor of fear contracting COVID-19 among the participants. This finding was related to the research study conducted by Margetic et al. (2021), in which avoidant emotional coping was revealed as a significant predictor of emotional distress and fear.

The statistical analysis on demographic variables also provided important and interesting findings that helped understand the participants' characteristics and their effects on Fear and Stress.

The present study results revealed that females experienced more fear than males during the lockdown condition of COVID-19. Linked with the present research findings, females experienced significantly greater fear than men in a research conducted on the Cuban population to compare fear of COVID-19 between genders (Broche-Pérez et al., 2020). Furthermore, another research conducted on American adults to investigate social vulnerabilities for fear revealed supporting the finding. Females were revealed as the most vulnerable respondents for experiencing fear, and a significant bivariate relationship was found between socially vulnerable respondents and fear (Filtzpatrick et al., 2020). Due to increased fear of contracting COVID-19, people have started exhibiting inappropriate social behaviors such as being paranoid and buying and stocking unnecessary households (Roy et al., 2020).

Stress is another important psychological implication of the Covid-19 lockdown that is studied in this study. Results revealed greater levels of stress in females than in male participants. This finding is supported by another research conducted to assess the statistics of gender differences related to stress in Canada. 30.5\% of female participants reported higher stress levels during the Covid-19 pandemic and $24.0 \%$ males in comparison because females felt more burden of unpaid family work, i.e., household chores such as laundry, cleaning, and taking care of their children than their male partner (Moyser, 2020).

Exposure to social media related to COVID-19 news alerts during lockdown affected the mental health of individuals (Holman et al., 2014). The present study results suggested, as the average time spent on social media increases, the stress in the participants also increases. It correlates with the findings of Roy et al. (2020), who inferred that exposure to social media during COVID-19 lockdown also caused distress among the individuals. Almost half of the participants (44.7\%) in their research study reported feelings of distress due to print media exposure and use of electronic media related to COVID-19 pandemic alerts and news updates about precautions and preventive measures.

Another important finding of this study is that participants whose family members were of older age group (e.g., above 50 years) were more fearful than those whose family members were of a younger age group. This concerning behavior for loved ones and family members was also reported in the research study conducted by Mertens et al. (2020) in which personal concern of risk for their 
grandparents was found to be a significant predictor of fear of coronavirus pandemic. Moreover, the risk for loved ones was revealed as one of the four predictors for fear of contracting COVID-19. Furthermore, the Ministry of Health Services Regulations and Coordination by the government of Pakistan (NHSRCGOP, 2020) also issued some additional instructions for caregivers, attendants, or family members of older individuals to ensure extra care, strong infection prevention measures, checking the health status regularly and monitoring their medicine intake for prevention of COVID-19 infection. Because of all these measures, the caregivers or family members of the elderly became more conscious and fearful of contracting Covid-19 infection.

The present study inferred that participants having family members with a history of the biological disease (heart disease, diabetes, pneumonia, asthma, hepatitis etc.) reported themselves more fearful than others who have family members with no history of biological disease. This finding is in accordance with the United Nations (2020) Report in which older individuals are described as the most vulnerable for the risk of COVID-19 infection, particularly those having a chronic illness such as diabetes, heart diseases, and hypertension, etc. therefore, this can be a reason for the participant's fear of contracting COVID-19 for their family members.

An important factor in this study is that participants who previously attended any stress management training were less stressed and fearful of contracting COVID19 compared to those who didn't attend. It is a new finding in this research as previously documented research data didn't provide any information regarding this aspect, especially in Asian culture during the lockdown condition of the COVID-19 pandemic. Concerning this finding, WHO (2020) provided an Illustrated Guide on its web page that includes audio files including instructions and techniques to deal with the stress during the COVID-19 pandemic. Moreover, mindfulness-based stress reduction training was proved to be very helpful in reducing stress, fear, and negative health consequences, as suggested by Sharma and Rush (2014) in a systematic review.

\section{Conclusion and Recommendations}

The present research highlighted the predicting relationship of subscales of cognitive appraisals and coping for Stress and Fear of contracting COVID-19 that will help community health workers, psychologists, and counselors deal with the pandemic sufferers. Moreover, the present research targeted the working people from different professions that will help the administrative bodies and government authorities to take reformative steps in their institutions to improve the psychological wellbeing of their employees.

The results revealed stress and fear of contracting COVID-19 among the participants, which needs to be treated by mental health professionals by analyzing the revealed coping strategies of active emotional, avoidant emotional, and problemfocused strategies. The present study results emphasize the need to raise awareness 
and up-gradation of our E-Government activities that will help address the general public's emotional and psychological problems. There is a crucial need to activate telehealth services in Pakistan to address the people's apprehensions, fears, stress, and other psychological problems, as most of our developed countries have started providing community health services to the rural and urban population. It directs the public policymakers to prepare first aid mental health treatments for emergencies, epidemics, or pandemics in the future.

\section{Limitations}

This study is a cross-sectional study; therefore, it is difficult to accurately interpret the causal relationship among these variables of the COVID-19 outbreak. Therefore, additional longitudinal studies are needed in this context. The data was collected during a short time, keeping in mind the rapid impact of COVID-19 on participants' coping behaviors and how they reacted to this stressor. It may be debated that the coping patterns and public reactions towards this outbreak may alter with time and with the possible treatment of COVID-19. The present study mainly focused on assessing public responses during COVID-19 but could not address the impact of government policies that might affect participants' responses. Therefore, the participants' responses could be better understood by assessing the efficacy of administrative measures taken by the government during COVID-19.

Data Availability All data generated or analysed during this study are included in this article.

\section{Declarations}

Conflict of interest The author declare that they have no conflict of interests.

\section{References}

Alhurani, A. S., Dekker, R., Ahmad, M., Miller, J., Yousef, K. M., Abdulqader, B., Salami, I., Lennie, T. A., Randall, D. C., \& Moser, D. K. (2018). Stress, cognitive appraisal, coping, and event free survival in patients with heart failure. Heart \& Lung: THe Journal of Critical Care, 47(3), 205-210. https://doi.org/10.1016/j.hrtlng.2018.03.008

Ali, A., Abbas, S., Khan, A. A., Ullah, S., \& Khan, A. S. (2021). Development and validation of an indigenous scale of the fear contracting COVID-19. Journal of Pakistan Society of Internal Medicine, 2(2), 140-144.

Anadolu. (2020, April 1). Pakistan extends lockdown to April 14. The Nation. https://nation.com.pk/01Apr-2020/pakistan-extends-lockdown-to-stem-coronavirus-spread

Babore, A., Lombardi, L., Viceconti, M. L., Pignataro, S., Marino, V., Crudele, M., Candelori, C., Bramanti, S. M., \& Trumello, C. (2020). Psychological effects of the COVID-2019 pandemic: Perceived stress and coping strategies among healthcare professionals. Psychiatry Research. https://doi.org/10.1016/j.psychres.2020.113366

Broche-Pérez, Y., Fernández-Fleites, Z., Jiménez-Puig, E., Fernández-Castillo, E., \& Rodríguez-Martin, B. C. (2020). Gender and fear of COVID-19 in a cuban population sample. International Journal of Mental Health and Addiction. https://doi.org/10.1007/s11469-020-00343-8

Busby, E. (2019, February 25). Teachers suffer more stress than other workers, study finds. Independent. https://www.independent.co.uk/news/education/education-news/teachers-stress-profession als-mental-health-workload-national-foundation-educational-research-a8795691.html 
Carver, C. S. (1997). You want to measure coping but your protocol's too long: Consider the brief COPE. International Journal of Behavioral Medicine, 4(1), 92-100. https://doi.org/10.1207/ s15327558ijbm0401_6

Chew, Q. H., Wei, K. C., Vasoo, S., Chua, H. C., \& Sim, K. (2020). Narrative synthesis of psychological and coping responses towards emerging infectious disease outbreaks in the general population: practical considerations for the COVID-19 pandemic. Tropical Journal of Singapore Medical Journal, 61(7), 350-356.

Cohen, S., Kamarck, T., \& Mermelstein, R. (1983). A global measure of perceived stress. Journal of Health and Social Behavior, 24(4), 385-396. https://doi.org/10.2307/2136404

Dewe, P. (1991). Primary appraisal, secondary appraisal and coping: Their role in stressful work encounters. Journal of Occupational Psychology. https://doi.org/10.1111/j.2044-8325.1991. tb00564. $x$

Ducharme, J. (2020, March 3). World Health Organization Declares COVID-19 a 'Pandemic.' Here's What That Means. Time. https://www.msn.com/en-us/news/world/world-health-organizationdeclares-covid-19-a-pandemic-heres-what-that-means/ar-BB112VyT

Durak, M., \& Senol-Durak, E. (2013). The development and psychometric properties of the Turkish version of the Stress Appraisal Measure. European Journal of Psychological Assessment, 29(1), 64-71. https://doi.org/10.1027/1015-5759/a000079

Egunjobi, P. J. (2020). The perception of covid-19 as a fear factor in the preparation for the pandemic aftermath. https://doi.org/10.13140/RG.2.2.14933.17125

Fitzpatrick, K. M., Harris, C., \& Drawve, G. (2020). Fear of COVID-19 and the mental health consequences in America. Psychological Trauma: Theory, Research, Practice, and Policy., 12(S1), S17-S21. https://doi.org/10.1037/tra0000924

Holman, E. A., Garfin, D. R., \& Silver, R. C. (2014). Media's role in broadcasting acute stress following the Boston Marathon bombings. Proceedings of the National Academy of Sciences, 111(1), 93-98. https://doi.org/10.1073/pnas.1316265110

Khatak, D. (2020, April 11). I Fear Hunger More Than The Virus': Pakistan's Delicate COVID-19 Balance. Radio Free Europe/Radio Liberty. https://www.rferl.org/a/coronavirus-pakistan-delic ate-balance-lockdown-economy-resistance/30547870.html

Khattak, J. K., Khan, M. A., Haq, A. U., Arif, M., \& Minhas, A. A. (2011). Occupational stress and burnout in Pakistans banking sector. African Journal of Business Management, 5(3), 810-817. https://doi.org/10.5897/AJBM10.395

Lazarus, R. S., \& Folkman, S. (1986). Cognitive theories of stress and the issue of circularity. In M. H. Appley \& R. Trumbull (Eds.), The Plenum series on stress and coping Dynamics of stress Physiological, psychological, and social perspectives. Delhi: Plenum Press.

Lazarus, R. S., \& Folkman, S. (1987). Transactional theory and research on emotions and coping. European Journal of Personality, 1(3,Spec Issue), 141-169.

Lazarus, S. R., \& Folkman, S. (1984). Stress Appraisal and Coping. Library of Congress.

Li, J., Yang, A., Dou, K., Wang, L., Zhang, M., \& Lin, X. (2020). Chinese public's knowledge perceived severity, and perceived controllability of the COVID-19 and their associations with emotional and behavioural reactions social participation and precautionary behaviour: A national survey. BMC Public Health, https://doi.org/10.31234/osf.io/5tmsh

Lockdown. (2020). In Cambridge Dictionary. https://dictionary.cambridge. org /dictionary/english/ lockdown

Man, M. A., Toma, C., Motoc, N. S., Necrelescu, O. L., Bondor, C. I., Chis, A. F., Lesan, A., Pop, C. M., Todea, D. A., Dantes, E., Puiu, R., \& Rajnoveanu, R. M. (2020). Disease perception and coping with emotional distress during COVID-19 pandemic: A survey among medical staff. International Journal of Environmental Research and Public Health, 17(13), 4899. https://doi. org/10.3390/ijerph17134899

Margetić, B., Peraica, T., Stojanović, K., \& Ivanec, D. (2021). Predictors of emotional distress during the COVID-19 pandemic; a Croatian study. Personality and Individual Differences, 175, 110691. https://doi.org/10.1016/j.paid.2021.110691

Mertens, G., Gerritsen, L., Duijndam, S., Salemink, E., \& Engelhard, I. M. (2020). Fear of the coronavirus (COVID-19): Predictors in an online study conducted in March 2020. Journal of Anxiety Disorders. https://doi.org/10.1016/j.janxdis.2020.102258

Ministry of National Health Services, Regulation \& Coordination, Government of Pakistan. (2020, June 2). Care of Old Patients in Wake of COVID-19. (Document Code: 35-01). Islamabad, 
Pakistan: Government of Pakistan. http://www.nhsrc.gov.pk/SiteImage/Misc/files/Patients-inWake-of\%20COVID.pdf

Moran, C. C., \& Hudges, P. L. (2006). Coping with stress: Social work students and humour. Social Work Education, 25(5), 501-517. https://doi.org/10.1080/02615470600738890

Moran, C. C. \& Massam, M. (1997) 'An evaluation of humour in emergency work', The Australasian Journal of Disaster and Trauma Studies, 3, 26-38. https://www.massey.ac.nz/ trauma/issues/ 1997-3/moran1.htm

Moyser, M. (2020, July 9). Gender differences in mental health during the COVID-19 pandemic. StatCan COVID-19: Data to Insights for a Better Canada, catalogue no. 45-28-0001. Ottawa: Statistics Canada. https://www150.statcan.gc.ca/n1/en/pub/45-28-0001/2020001/article/00047-eng. pdf?st=la1bDits

National Association of School Psychologists. (2018). Mitigating Negative Psychological Effects of School Lockdowns: Brief Guidance for Schools. Bethesda, MD: Author. file://C:/Users/Shah/ Downloads/Mitigating_Psychological_Effects_of_Lockdowns.pdf

Peacock, E. J., \& Wong, P. T. P. (1990). The Stress Appraisal Measure (SAM): A multidimensional approach to cognitive appraisal. Stress Medicine, 6, 227-236. http://www.drpaulwong.com/wpcontent/uploads/2018/03/Stress-Appraisal-Measure-SAM-Peacock-Wong-1990-Paper.pdf

Qiu, J., Shen, B., Zhao, M., Wang, Z., Xie, B., \& Xu, Y. (2020). A nationwide survey of psychological distress among Chinese people in the COVID-19 epidemic: Implications and policy recommendations. General Psychiatry. https://doi.org/10.1136/gpsych-2020-100213

Roy, D., Tripathy, S., Kar, S. K., Sharma, N., Verma, S. K., \& Kaushal, V. (2020). Study of knowledge, attitude, anxiety \& perceived mental healthcare need in Indian population during COVID19 pandemic. Asian Journal of Psychiatry, 51, 102083. https://doi.org/10.1016/j.ajp.2020. 102083

Shanahan, L., Steinhoff, A., Bechtiger, L., Murray, A. L., Nivette, A., Hepp, U., Ribeaud, D., \& Eisner, M. (2020). Emotional distress in young adults during the COVID-19 pandemic: Evidence of risk and resilience from a longitudinal cohort study. Psychological Medicine. https://doi.org/10. 1017/S003329172000241X

Sharma, M., \& Rush, S. E. (2014). Mindfulness-based stress reduction as a stress management intervention for healthy individuals: A systematic review. Journal of Evidence-Based Complementary \& Alternative Medicine, 19(4), 271-286. https://doi.org/10.1177/2156587214543143

Thornton, P. I. (1992). The relation of coping, appraisal, and burnout in mental health workers. The Journal of Psychology: Interdisciplinary and Applied, 126(3), 261-271. https://doi.org/10.1080/ 00223980.1992 .10543360

United Nation. (2020). Everyone Included: Social Impact of COVID-19. UN. Department of Economics and Social Affairs, Social Inclusion. https://www.un.org/development/desa/dspd/everyoneincluded-covid-19.html

Usher, K., Durkin, J., \& Bhullar, N. (2020). The COVID-19 pandemic and mental health impacts. International Journal of Mental Health Nursing, 29(3), 315-318. https://doi.org/10.1111/inm. 12726

World Health Organization. (2020, April). Doing What Matters in Times of Stress. https://www.who. int/publications/i/item/9789240003927?gclid=EAIaIQobChMI7aWYzb796wIViOJ3Ch2p3gU QEAAYASAAEgKd2PD_BwE

World Health Organization. (n.d.). Coronavirus. Retrieved April 27 , 2020, from https://www.who.int/ health-topics/coronavirus\#tab=tab_1

Zheng, W. (2020). Mental health and a novel coronavirus (2019-nCoV) in China. Journal of Affective Disorders, 269, 201-202. https://doi.org/10.1016/j.jad.2020.03.041

Publisher's Note Springer Nature remains neutral with regard to jurisdictional claims in published maps and institutional affiliations. 


\section{Authors and Affiliations}

\section{Anam Ali ${ }^{1}$ (D) Ali Asad Khan ${ }^{2} \cdot{\text { Sadia } \text { Abbas }^{3} \cdot \text { Ali Salman Khan }}^{4} \cdot$ Ehsan Ullah $^{1}$}

$\triangle$ Anam Ali

anam.ali90@hotmail.com

1 Department of Developmental \& Behavioral Pediatrics, The Children's Hospital \& The Institute of Child Health (CH\&ICH), Lahore, Pakistan

2 North Medicine Unit, King Edward Medical University, Lahore, Pakistan

3 Center for Clinical Psychology, University of the Punjab, Lahore, Pakistan

4 Acute Medical Unit, North Manchester General Hospital, Manchester, England 